\title{
Correction to: Prolonging the Shelf Life of Cherry Tomatoes by Pullulan Coating with Ethanol Extract of Propolis during Refrigerated Storage
}

\author{
Katarzyna Pobiega ${ }^{1}$ (D) Jarosław L. Przybył ${ }^{2}$ (D) Joanna Żubernik ${ }^{3}$ (D) Małgorzata Gniewosz $^{1}$ (D) \\ Published online: 21 July 2020 \\ (C) Springer Science+Business Media, LLC, part of Springer Nature 2020
}

Correction to: Food Bioprocess Technol 2020;13(7):1447-1461.

https://doi.org/10.1007/s11947-020-02487-w

The original version of this article unfortunately had typo error in one of the author's name.

The name Małgorzta Gniewosz should be corrected to "Małgorzata Gniewosz".

Publisher's Note Springer Nature remains neutral with regard to jurisdictional claims in published maps and institutional affiliations.

The online version of the original article can be found at https://oi.org/ 10.1007/s11947-020-02487-w

Katarzyna Pobiega

katarzyna_pobiega@sggw.edu.pl

Jarosław L. Przybył

jaroslaw_przybyl@sggw.edu.pl

Joanna Żubernik

joanna_zubernik@sggw.edu.pl

Małgorzata Gniewosz

malgorzata_gniewosz@sggw.edu.pl

1 Department of Food Biotechnology and Microbiology, Institute of Food Sciences, Warsaw University of Life Sciences SGGW, 159c Nowoursynowska str, 02-776 Warsaw, Poland

2 Department of Vegetable and Medicinal Plants, Institute of Horticulture Sciences, Warsaw University of Life Sciences SGGW, 159 Nowoursynowska str, 02-776 Warsaw, Poland

3 Department of Food Engineering and Process Management, Institute of Food Sciences, Warsaw University of Life Sciences SGGW, 159c Nowoursynowska str, 02-776 Warsaw, Poland 